\title{
Políticas públicas e desenvolvimento: uma proposta de modelo de análise
}

\author{
Public policies and development: an analysis model \\ proposal
}

\author{
Luciana Leite Lima [a] (D), Luciano D'Ascenzi [b] [D), \\ Lizandro Lui [c] (iD), Rafael Barbosa de Aguiar [a,d] [D
}

[a] Universidade Federal do Rio Grande do Sul (UFRGS), Departamento de Sociologia, Programa de Pós-graduação em

Políticas Públicas, Porto Alegre, RS, Brasil

[b] Agência Estadual de Regulação dos Serviços Públicos Delegados do Rio Grande do Sul (AGERGS), Porto Alegre, RS, Brasil

[c] Fundação Getúlio Vargas (FGV-Brasília), Programa de Pós-Graduação em Políticas Públicas e Governo, Brasília, DF, Brasil

[d] Prefeitura Municipal de São Bento do Sapucaí, Secretaria de Planejamento e Gestão, São Bento do Sapucaí, SP, Brasil

Como citar: Lima, L. L., D’Ascenzi, L., Lui, L. \& Aguiar, R. B. (2021). Políticas públicas e desenvolvimento: uma proposta de modelo de análise. urbe. Revista Brasileira de Gestão Urbana, v.13, e20210048. https://doi.org/10.1590/21753369.013.e20210048

\section{Resumo}

Este artigo apresenta uma proposta de modelo para analisar políticas públicas a partir de seu impacto em termos de desenvolvimento multidimensional. Assume-se que as políticas são iniciativas voltadas à transformação social, e que o desenvolvimento pode lhes dar sentido e direção. 0 modelo está fundamentado na perspectiva do desenvolvimento endógeno e da governança, de onde derivamos dois conjuntos de categorias analíticas. A primeira, endogeneidade, leva o olhar para a agência dos atores locais que, de fato, produzem os processos e sofrem as consequências das ações correspondentes. Ela foi desdobrada em três dimensões analíticas: equidade, sustentabilidade e participação. Interessa aqui investigar as potencialidades das políticas para realizar aquilo que justifica sua existência: melhorar a vida em sociedade. Por seu turno, os mecanismos de governança, segundo conjunto, enfocam os processos de construção das políticas, averiguando a manifestação do caráter endógeno na tomada de decisão. Também decomposto em três dimensões de análise: participação, consensualidade e gestão mista. A proposta almeja contribuir para o fortalecimento do campo de análise de políticas públicas no Brasil e, de forma relacionada, oferecer uma perspectiva que atente para as políticas a partir do resultado que as tornam fundamentais em nossa sociedade.

Palavras-chave: Mudança social. Políticas públicas. Modelo analítico. Desenvolvimento.

LLL é professora, doutora em Ciências Sociais, e-mail: lucianaleitelima@gmail.com

LD é técnico superior, doutor em Ciências Sociais, e-mail: luciano.dascenzi@gmail.com

LL é professor, doutor em Sociologia (UFRGS), e-mail: lizandrolui@gmail.com

RBA é secretário de Planejamento e Gestão, doutorando e mestre em Políticas Públicas, e-mail: rafaelba@yahoo.com.br 


\section{Abstract}

This paper presents a model to analyze public policies on their impact in terms of multidimensional development. It is assumed that policies are initiatives toward the social transformation, and that development can give it meaning and direction. The model was designed based on endogenous development and governance approaches, from which we derived two sets of analytical categories. The first, endogeneity, directs its attention toward the agency of local actors who perform the processes and bear the consequences of such policies. Endogeneity was unfolded into three analytical dimensions: equity, sustainability and participation. So, this analytical category allows us to investigate the potentialities of policies to accomplish what justifies their existence: improving social conditions. The second, governance mechanisms, focus on policymaking processes, exploring the manifestation of endogenous character in decision-making, divided into three dimensions of analysis: participation, consensus and shared management. The proposal aims to strengthen policy analysis in Brazil and, thus, to offer a perspective that pays attention to policies based on the results that make them fundamental in our society.

Keywords: Social change. Public policies. Analytical model. Development.

\section{Introdução}

As políticas públicas são reconhecidas como instrumentos sociais importantes para o enfrentamento dos problemas públicos e para a promoção do desenvolvimento (Gomide \& Pereira, 2018; Pires, 2019b; Souza, 2006). Tal relevância incentiva a crescente atenção que o campo da policy analysis vem recebendo no Brasil nas últimas décadas (Marques \& Faria 2013; Vendramini \& Almeida 2017; Farah, 2018). De forma geral, a análise de políticas públicas volta-se ao entendimento da emergência, das estruturas, das dinâmicas e dos resultados previstos e imprevistos dessas iniciativas, sejam elas protagonizadas pelo Estado ou por grupos sociais. Esse esforço tem por finalidade ampliar o conhecimento acerca desses fenômenos, bem como colaborar para o incremento de seu desenho e implementação (Bardach, 2012; Nogueira \& Forte, 2019; Peters, 2015; Reis, 2003).

Nessa direção, o objetivo deste artigo é delinear um modelo para analisar as políticas públicas a partir de seu impacto, modelado em termos de desenvolvimento, entendido em uma perspectiva multidimensional. Nessa concepção, o desenvolvimento corresponde a um processo de melhoria nas condições de vida em sociedade, de forma a produzir relações mais justas, igualitárias e equitativas (Inglehart \& Welzel, 2009; Sen, 2010a; Sen \& Kliksberg, 2010). Pensado dessa forma, ele assume contornos amplos, abarcando diversas dimensões da sociabilidade (Heidemann, 2014; Mauro et al., 2018; Sen, 2010a). Tal visão se coaduna com a definição de políticas públicas que as concebe enquanto iniciativas voltadas à transformação de uma realidade social percebida como problemática. Por conseguinte, assume-se que as políticas públicas têm potencial para provocar mudanças sociais, e que o desenvolvimento multidimensional pode qualificar seu sentido e direção.

Na literatura nacional, é possível encontrar trabalhos que propõem modelos para analisar as políticas públicas a partir das policy arenas (Frey et al. , 2017), de seus arranjos institucionais (Lotta \& Favareto, 2016), bem como de fases específicas, como a implementação (Draibe 2001; Pires 2019b) e a avaliação (Boullosa \& Rodrigues, 2014; Rodrigues, 2008). Também, a literatura internacional oferece diversas abordagens. A mais popular é o ciclo de políticas públicas, que apresenta as políticas em etapas, explicitando a especificidade de cada uma. Outras perspectivas recebem atenção, como a dos múltiplos fluxos, do equilíbrio pontuado e das coalisões de defesa, as quais abordam as políticas a partir dos atores e suas interações, incluindo ideias, interesses e contextos institucionais (Capano \& Howlett, 2020).

Todas estas perspectivas contribuem para ampliar nosso entendimento sobre as políticas públicas. 0 presente artigo almeja colaborar com estes esforços, propondo um quadro analítico para compreender as políticas. Porém, o que o diferencia dos demais é o movimento de investigá-las a partir de seus efeitos sociais e de derivar as categorias analíticas de uma perspectiva de desenvolvimento, permitindo averiguar se os esforços empreendidos por meio das políticas seriam capazes de produzir mudanças sociais nesse sentido. 
Isto é, as teorias citadas atentam para as instituições, os atores e suas ideias e interesses, bem como para fases específicas das políticas, entendendo os resultados destas como produtos daquelas variáveis. Em contraste, nesta proposta, tomamos como ponto de partida os impactos desejados para então observar as instituições, os atores e as organizações. Especificamente, sugerimos analisar as políticas públicas a partir do impacto em termos de desenvolvimento, entendido em uma perspectiva multidimensional.

Para isso, mobilizamos uma abordagem de desenvolvimento que valoriza as especificidades dos agentes e dos territórios envolvidos no processo de mudança; e uma perspectiva de governança que enfoca as arenas nas quais a diversidade de atores interage, estabelecendo coalisões e promovendo coordenação e objetivos comuns. Desses fundamentos teóricos e conceituais derivamos as categorias e dimensões analíticas que orientam esta proposta. Com isso, buscamos apresentar um modelo alinhado à lógica bottom$u p$, que valoriza as especificidades locais, a participação social e a endogeneidade.

Tal construção será desdobrada a seguir. No tópico que segue, trataremos da definição de políticas públicas que embasa o modelo. A terceira e a quarta parte discorre sobre teorias e conceitos basilares. Complementarmente, a quinta, apresenta as categorias e as dimensões analíticas derivadas, permitindo contribuir antecipadamente quanto às possibilidades de desenvolvimento multidimensional das mais variadas políticas. Por fim, algumas considerações finais.

\section{Políticas Públicas: uma definição subjacente à proposta}

Na literatura do campo é possível encontrar diversos entendimentos para o termo políticas públicas, uma variedade que oferece ao analista a possibilidade de enfatizar suas diferentes dimensões. Neste tópico são examinadas algumas definições relevantes, de onde extraem-se elementos para o conceito que fundamenta o modelo proposto. Assim, o intuito não foi realizar uma revisão exaustiva da literatura, mas apontar as diferentes dimensões que as definições proporcionam para a análise. Vamos a elas.

Algumas concepções de políticas públicas realçam seu propósito, como em Peters (2015): política pública é o conjunto de atividades que os governos empreendem com a finalidade de mudar sua economia e sociedade indistintamente. Aqui, as análises baseiam-se num entendimento de que a função das políticas públicas seria promover transformações sociais. Ilustrativamente, podemos citar outras definições que se desenvolvem nesse sentido: “A formulação de políticas públicas constitui-se no estágio em que os governos democráticos traduzem seus propósitos e plataformas eleitorais em programas e ações que produzirão resultados ou mudanças no mundo real" (Souza, 2006, p. 26); "As políticas sociais têm três funções principais: a criação de capital humano, a compensação social e o apoio à integração dos indivíduos na sociedade" (Cohen \& Franco, 2007, p. 40); "Pode-se dizer que as políticas públicas, [...], dão partida a um circuito de influências bastante complexo em diversos fatores do desenvolvimento" (Castro \& Oliveira, 2014, p. 23); "O presente estudo assume que as políticas de transferência de renda condicionada foram, em significativa medida, responsáveis por esses resultados [redução da pobreza e da desigualdade]" (Ferrarezi \& Rua, 2018, p. 63). Deste conjunto, destacamos que a efetividade de uma política requer uma visão holística. Do tipo que entende seu impacto frente à estruturação social e o enforcement necessário à mudança.

Sob outro ângulo, uma das definições mais conhecidas é a de Dye (2010): política pública é tudo o que os governos escolhem fazer ou não fazer. 0 autor procura se afastar das acepções que, a priori, vinculam as políticas com problemas sociais ou com objetivos formais de implementação. Ele argumenta que tais ligações nem sempre existem; elas expressariam muito mais nosso desejo de imprimir alguma racionalidade funcional na ação governamental do que das características intrínsecas desta. Por isso, Dye (2010) enfatiza aquilo que podemos observar: as ações e as inações do Estado. Essa noção, ao mesmo tempo que é abrangente, coloca foco no ator governamental, delimitando a política pública a partir de sua inciativa, seja de agir ou de não agir. Embora tal conceito se mostre adequado às necessidades aqui propostas, nossa construção comporta uma definição mais abrangente quanto ao ator da (in)ação.

Outra forma de entender as políticas, encontramos em Muller \& Surel (2002, p. 11), que sugerem uma acepção que valoriza o aspecto processual: "processo pelo qual são elaborados e implementados programas 
de ação pública, isto é, dispositivos político-administrativos coordenados em princípio em torno de objetivos explícitos". De forma semelhante, Howlett et al. (2013, p. 12) destacam que a política pública "consiste em inúmeras decisões tomadas por muitos indivíduos e organizações no interior do próprio governo e que essas decisões são influenciadas por outros atores". Estas definições valorizam os processos decisórios, levando o olhar para os atores e suas interações; podendo também abrir espaço para uma discussão sobre a influência das instituições. A primeira, ainda, oferece um pressuposto de vinculação entre a política e os objetivos perseguidos durante a implementação. Sobre isso, há alguma controvérsia acerca da capacidade dos objetivos iniciais de sobreviver ao longo da cadeia de implementação (Lotta, 2019). Toda essa discussão nos é relevante, tendo em vista a devida contextualização, mas não quanto à necessidade de relacionar objetivos e elementos ou fases da política.

Outra discussão recorrente dá-se na ligação entre política pública e problema social. Nesse sentido, Hill \& Hupe (2014) consideram que as noções de política pública indicam um caráter intencional em relação com os problemas sociais. Similarmente, mas a partir de outra perspectiva, Secchi (2015, p. 2) destaca que uma política é "uma diretriz elaborada para enfrentar um problema público". Tais ideias evidenciam a natureza problem-solving das políticas. Uma decorrência do alinhamento a este tipo de definição é a necessidade de demonstrar a relação de causalidade entre a existência de determinado problema e a proposta de solução na forma de política pública correspondente. No entanto, Kingdon (1995) demonstra que os processos de construção social do problema público, de elaboração da política, bem como da atividade política, exibem um grau não desprezível de independência entre si, cada qual contando com atores e dinâmicas próprias. Bem por isso, esta proposta visa a não interferir nas questões setoriais das eventuais políticas estudadas, cuja eficácia não resta discutida ou analisada. Distintamente dessa fragmentação originária, nossa proposta identifica o desenvolvimento multidimensional como uma condição social holística, integrando as políticas umas às outras frente a este objetivo maior, quanto às possibilidades de gerar impacto desconcentrado ou efetividade (Lima \& D’Ascenzi, 2019). Nesse sentido, definiremos as políticas a partir da ambição por transformar uma realidade social percebida como inadequada ou indesejável pelos agentes. Assim, acentuamos uma das bases de legitimidade das políticas: sua função social. Afinal, porque desejamos, fazemos e defendemos políticas públicas? Porque acreditamos que elas são instrumentos por meio dos quais podemos melhorar a vida em sociedade; ou especificamente: reduzir desigualdades (Arretche, 2016), promover a equidade (Cohen \& Franco, 2007) e gerar desenvolvimento (Evans, 2004; Kliksberg, 1997; Lucio et al., 2017; Rodrigues \& Beserra, 2017).

Argumentamos que tal acepção permitiria contemplar as peculiaridades dos diferentes setores de políticas públicas, já que foca naquilo que tal diversidade enseja, a mudança social. Mas em qual sentido? Com essa pergunta em mente, avancemos, agora, para a delimitação das dimensões das políticas que seriam valorizadas no modelo proposto.

\section{Dos Fundamentos Teóricos e Conceituais do Modelo}

Logo de início, vamos trabalhar com a ideia de que as políticas públicas são dirigidas à mudança social, especialmente no sentido do incremento do bem-estar social, o que provê um grau de liberdade considerável. Ademais, a retirada dos elementos restritivos à definição empregada permite analisar um leque de políticas e matrizes indefinido. Nesse caminho, modelamos a mudança social em termos de desenvolvimento multidimensional, pois envolve a inter-relação de dimensões apriorísticas da sociabilidade como elemento central à análise.

Cabe frisar que a literatura sobre desenvolvimento é longeva, perpassando diferentes campos de conhecimento; e que não pretendemos fazer aqui uma sistematização, pois muitas já foram realizadas. A título de ilustração, e considerando somente a literatura nacional recente tem-se: Mauro et al. (2018), Neto (2014), Santos e Carniello (2014), Pimenta (2014), Barros e Castro (2013), Santos et al. (2012), Vieira \& Santos (2012), Dallabrida (2011), Radomsky \& Francisco (2011). 
Para nossos fins, destacamos desse campo a teoria do desenvolvimento endógeno. Tal abordagem foi elaborada a partir da década de 1980 com o intuito de compreender as novas atribuições das cidades e regiões da América Latina e de países europeus de desenvolvimento tardio num contexto de globalização e descentralização política (Tapia, 2005; Vázquez Barquero, 2001). Nesse sentido, um conjunto de pesquisadores empreendeu esforços para formular teorias de médio alcance, metodologias e estudos empíricos voltados à realidade do território (Docampo, 2007a). Além da aproximação contextual, essa perspectiva se torna interessante na medida em que lança luz sobre os aspectos endógenos dos processos de desenvolvimento, isto é, considera a cultura, as instituições e a agência dos atores locais. Essa é uma questão assaz relevante em regimes democráticos, nos quais a participação surge como princípio, valor e instrumento de políticas públicas (Abers et al., 2018; Lavalle et al. 2016).

A partir de Albuquerque (2004), Docampo (2007b) e Vázquez Barquero (2007), definimos o desenvolvimento endógeno como um processo de mudança, liderado pela comunidade local, que relaciona o potencial de desenvolvimento existente no território às oportunidades externas, gerando efeito multiplicador, e incremento de bem-estar na população. Tal acepção dirige a atenção para o resultado desconcentrado dos esforços empreendidos, assim como para a forma de produzir tal efeito.

Nesta perspectiva, não há que se falar em bem-estar social sem o envolvimento das pessoas, seja no seu entendimento, seja na sua consecução. Na base desta ideia está uma concepção de agência em linha com Sen (2010a, p. 34): “[agente é] alguém que age e ocasiona mudança e cujas realizações podem ser julgadas de acordo com seus próprios valores e objetivos, independentemente de as avaliarmos ou não também segundo algum valor externo". Tal conceito carrega a dimensão da subjetividade, a qual se manifesta em termos de intersubjetividade quando em contextos sociais de debate a respeito das preferências e interesses acerca do futuro almejado. Desse modo, o exercício da condição de agente implica perceber o papel ativo das pessoas, que não são apenas receptoras passivas de políticas, mas são as responsáveis pela mudança e aquelas que sofrerão suas consequências (Sen, 2010a; Sen \& Kliksberg, 2010).

Pensar o desenvolvimento a partir dessa lente, permite tratá-lo como uma categoria local emergente, isto é, forjada nas relações entre os atores, expressando, dessa maneira, entendimentos intersubjetivos, as características do local, bem como as interações estabelecidas e potenciais com o entorno, independentemente da escala regional, nacional ou global. Nesse ponto, se explicita a concepção de sociedade necessária: “a 'sociedade' não é uma entidade e não tem uma presença espácio-temporal; ela existe apenas como práticas sociais reproduzidas em uma diversidade indefinida de meios" (Giddens, 1998, p. 21). Somado a isso, é necessário trazer a concepção cognitiva, ou seja, a política e o desenvolvimento não são fins definidos a priori por outrem, mas resultado do processo de concertação social e entendimento dos atores sociais inseridos localmente.

Desse modo, enquanto padrão emergente, o desenvolvimento pode tomar muitas formas e objetivos, revelando seu caráter multidimensional, já que dependente das racionalidades, entendimentos, interesses, desejos, recursos e repertórios de ação relacionados aos atores locais. Como resultado, o delineamento da definição é um constructo político e de análise. Político porque é forjado nas relações sociais a partir do entendimento intersubjetivo e valorização de dados aspectos da realidade vivenciada; de análise porque recortado por meio do trabalho do analista, que deve especificar seus critérios e fundamentar a delimitação das fronteiras. Portanto, a definição é fruto e fonte de conflito, ou seja, de diferentes níveis de interação e consensualidade.

O conflito entre os atores é um pressuposto no campo da análise das políticas públicas. Entende-se que “a construção de políticas públicas não é um processo abstrato. Ela é, ao contrário, indissociável da ação dos indivíduos ou dos grupos envolvidos, de sua capacidade de produzir discursos concorrentes, de seus modos de mobilização" (Muller \& Surel, 2002, p. 77). Enquanto fruto da atividade política, "a essência da política pública [...] [é] o embate em torno de ideias e interesses" (Souza, 2007, p. 69).

A assunção da existência de diversos níveis de consensualidade, em um contexto de pluralidade de atores, conduz o olhar para os arranjos institucionais de governança. A relevância de espaços de concertação voltados à gestão compartilhada é recorrentemente apontada pela literatura sobre desenvolvimento sob o 
enfoque territorial (Brugué et al., 2005; Delgado \& Leite, 2011; Favareto \& Lotta, 2017). Nesse caminho, Evans (2004) e Tapia (2005) chamam a atenção para os mecanismos de governança: voltados ao estabelecimento e à atuação de coalizões estáveis, promovendo a coordenação das ações, a colaboração e a definição das prioridades e dos objetivos conjuntos.

De forma complementar, a teoria de Ostrom (1990), sistematizada posteriormente por Dietz et al. (2003), aborda o desafio da construção de estruturas institucionais que permitam que os atores inseridos em contextos locais desfrutem de benefícios coletivos e compartilhados ao longo do tempo. Em sua obra, Ostrom (1990) investiga como atores, em realidades sociais específicas, constroem um arcabouço de normas e regras que possibilitam o gerenciamento de recursos de uso comum e dos conflitos que derivam dessa dinâmica ao longo do tempo. Ela é categórica ao afirmar que, em certos casos, a institucionalização das políticas locais deve ser fruto da concertação entre os atores que vivenciam dada realidade, e não um constructo imposto de forma exógena. Novamente, a ideia de desenvolvimento de comunidades localizadas em um tempo e espaço definido aparece atrelada ao conceito de concertação derivada da participação social.

Ainda, os espaços de gestão compartilhada têm sido relacionados à qualificação e à democratização dos processos das políticas públicas (Bevir, 2013; Hill \& Hupe, 2014). Por outro lado, também são apontados seus limites em termos de inclusão da diversidade de agentes (Casula, 2017) e de manutenção de regras que permitam que tal pluralidade influencie as decisões (Borba \& Lüchmann, 2010). Sobre isso, a construção democrática é central na obra de Dagnino (2002), cujos Espaços Públicos configurariam um conjunto de características à construção democrática, analisada inicialmente em termos dos níveis de heterogeneidade de atores e de normatividade, procedimentos e mecanismos institucionais que visem a partilha efetiva de poder, enquanto elementos necessários à participação. Ademais, em relação à influência das instituições participativas sobre as políticas públicas, a literatura tem apontado que não há uma relação de causalidade direta e unidimensional entre a participação e a melhoria dos serviços prestados pelo Estado (Avritzer \& Souza, 2013; Abers et al. 2018; Leal \& Lui, 2018). No entanto, a participação teria positividade intrínseca em virtude de expressar e reforçar os ideais democráticos.

Por último, reforçando a complementaridade e necessidade de espelhamento entre as categorias endógenas e os mecanismos de governança, tendo em vista o objetivo de produzir uma mudança social qualitativamente desejada, bem como sua consequente manutenção no tempo, sublinha-se a ideia de "círculo virtuoso" acionado por sinergias entre instituições políticas e econômicas inclusivas (Acemoglu \& Robinson, 2015). Senão, do processo de consolidação das chamadas "avaliações sociais" em meio às avaliações econômicas (Adachi, 2019; Rebelatto, 2004).

\section{Teorias para análise de políticas públicas}

Ao longo dos últimos 50 anos, um conjunto de lentes teóricas foram desenvolvidas para analisar as políticas públicas. Elas enfocam diversas dimensões: a natureza incremental das políticas, os processos decisórios e a racionalidade limitada, o papel das instituições e das regras do jogo na conduta dos atores sociais, as ideias e interesses nos processos das políticas etc. Nesse sentido, podemos destacar: tipo da política (Lowi, 1964), incrementalismo (Lindblom, 1979), ciclo das políticas públicas (Lasswell, 1956), modelo da "lata de lixo" (Cohen et al., 1972), coalisão de defesa (Sabatier \& Jenkins-Smith, 1993), múltiplos fluxos (Kingdon, 1995), equilíbrio pontuado (Baugartner \& Jones, 1993), Institutional Analysis and Development Framework (Ostrom, 1990), dentre outros. Apresentaremos brevemente algumas teorias clássicas.

Uma abordagem que ganhou bastante destaque na literatura é o ciclo das políticas públicas, desdobrado a partir do trabalho de Lasswell, (1956). Nele, as políticas públicas são tomadas como um ciclo deliberativo, constituindo um processo dinâmico e de aprendizado, sendo composto pelas seguintes etapas/estágios: definição de agenda, identificação de alternativas, avaliação das opções, seleção das opções, implementação e avaliação (Souza, 2006). Já o modelo dos múltiplos fluxos, desenvolvido por Kingdon (1995), procura analisar como situações indesejáveis se transformam em problemas percebidos 
como sociais, e como estes passam a receber atenção do público e dos políticos passando a integrar a agenda governamental. Assim, tal modelo destina-se a responder às seguintes questões: i) por que decisores políticos prestam atenção a um determinado assunto em detrimentos de outros? ii) como e por que se alteram as agendas políticas ao longo do tempo? iii) como decisores políticos selecionam soluções para os problemas dentre um vasto conjunto de alternativas? (Araújo \& Rodrigues, 2017). 0 modelo do equilíbrio pontuado foi concebido com base no princípio de que os processos políticos são, em geral, caracterizados por estabilidade e incrementalismo, interrompidos, eventualmente, por grandes mudanças nas políticas anteriores. Nesse sentido, a abordagem procura explicar tanto as descontinuidades ou interrupções quanto as continuidades/incrementalismos das políticas, argumentando que o mesmo sistema institucional é capaz de gerar das menores até as mais radicais mudanças (Araújo \& Rodrigues, 2017). Por sua vez, o modelo de coalizão de defesa entende a política pública como um conjunto de subsistemas relativamente estáveis, que se articulam com acontecimentos externos, os quais dão os parâmetros para os constrangimentos e os recursos de cada política pública. Nesse modelo, as crenças, valores e ideias integram as dimensões do processo de formulação das políticas públicas, assim cada subsistema de uma política pública é composto por um número de coalisões de defesa que se distinguem por essas dimensões e, também, pelos recursos que dispõem (Souza, 2006).

O que diferencia a proposta apresentada neste artigo destas abordagens, especialmente, é o foco de análise, que se direciona aos efeitos desejados das políticas, a partir do qual indaga-se sobre os atores e suas interações em contextos institucionais e organizacionais. As abordagens listadas acima enfocam atores, ideias, instituições e, a partir daí, depreendem conclusões sobre os resultados das políticas. Ainda, o modelo proposto aqui não se baseia na ideia de ciclo, o que é consequência do foco analítico. Por fim, cabe destacar a definição de política pública que nossa proposta mobiliza, a qual ressalta seu propósito de promoção de mudança social. Tal acepção sustenta o enfoque analítico.

De forma mais geral, o modelo clássico que mais dialoga com os fundamentos do modelo proposto aqui é o Institutional Analysis and Development (IAD) Framework, desenvolvido por Ostrom (1990). Sua principal preocupação era compreender como comunidades locais criavam estruturas institucionais para resolver problemas coletivos e administrar bens de uso comum. As variáveis analíticas sintetizadas por Polski e Ostrom (1999) para IAD Framework são: o mundo físico, a comunidade, as regras do jogo (entendidas como instituições pré-existentes), as arenas de ação em que os atores sociais se inserem, os padrões de interação desses atores e os critérios de avaliação dos mesmos sobre o processo.

Desse modo, o modelo de análise voltado a observar a capacidade das políticas públicas de promover desenvolvimento proposto guarda algumas similaridades com a perspectiva delineada por Ostrom (1990). Em primeiro lugar, não se trata de compreender como uma política formulada numa esfera de governo central é implementada nos contextos locais. Pelo contrário, o modelo de Ostrom e o aqui proposto partem da análise do ambiente de participação e concertação social em nível local. Além disso, os fatores ambientais e físicos importam em ambos os modelos, bem como de que modo as regras do jogo são compreendidas pelos atores sociais. As políticas voltadas à promoção do desenvolvimento endógeno estariam, em tese, lidando com recursos disponíveis e encontrando formas sustentáveis, eficientes e participativas de se efetuar. No tópico que segue, veremos tais ideias impressas na modelagem das categorias analíticas.

\section{Ativando o Modelo: categorias analíticas derivadas da teoria}

Das ideias e conceitos apresentados, resgatamos e expandiremos dois conjuntos de macro categorias que orientam o modelo de análise proposto: a endogeneidade e os mecanismos de governança. Elas estão sinergicamente relacionadas e, ao mesmo tempo, serão subdivididas em elementos distintos.

Como vimos, a endogeneidade enfoca o poder de agência das comunidades, permitindo examinar se os esforços empreendidos estão conectados às demandas, às necessidades e às capacidades locais. Para explorar tal aspecto nas políticas públicas, partiremos da sugestão de Docampo (2007b) e desagregaremos o conceito de endogeneidade em três dimensões: equidade, sustentabilidade e participação. 
A equidade abarca e contextualiza uma relação complexa entre igualdade e justiça social, correspondendo ao incremento das capacidades de agência, com maior potencial de crescimento junto aos atores mais vulneráveis. Docampo (2007b), a partir de Sen (2010a), relaciona a equidade ao desenvolvimento humano, ou seja, à ampliação das oportunidades e capacidades das pessoas para levarem a vida que desejam. Uma forma de abordar a equidade, no que tange às políticas públicas, seria por meio da focalização, acionando uma visão de justiça social (Farah, 2004; Kerstenetzky, 2006), que se diferencia da visão formal (restrita à legalidade) e da universal. Nesse ponto, se interconectam duas dimensões caras à gestão de políticas: a eficiência, enquanto processo, e a efetividade, como resultado desconcentrado. A primeira tange às formas de utilização dos recursos no processo de operacionalização da política; a segunda, aos resultados últimos desse processo, cuja consecução esta abordagem procura medir. Nesse sentido, a relação informa que os recursos, sendo limitados diante das demandas, devem ser direcionados: primeiro aos que experenciam menor capacidade de agir de forma a construírem a vida que valorizam, aqueles que sofrem mais e maiores privações (Sen, 2010b). De resto, apontando para uma maior focalização dos recursos empregados. A efetividade, por sua vez, diz respeito à transformação produzida, justamente a partir do esforço realizado, comparativamente ao estado original. Por fim, nada a ser dito sobre a eficácia, reservada à setorialidade da política originalmente desenhada. Isto é, a abordagem privilegia as possibilidades de integração sinérgica, assim efetiva, entre políticas e setores, sem imiscuir-se em cada particularidade finalística.

A sustentabilidade se refere à perspectiva ética geracional, ampliando o elemento conceitual da funcionalidade econômica. O tratamento tradicional dado à funcionalidade dos contextos de ação econômicos preocupa-se, prioritariamente, com a eficiência; quando muito com a eficácia. Isso significa tratar como exógenas, por exemplo, as falhas de mercado, bem como outras mazelas que justificam a regulação por parte do Estado. Aqui, em conformidade com a definição de sociedade de Giddens (1998), tais questões são endogeneizadas. Ou seja, em linha com a tendência iniciada no relatório Nosso Mundo Comum, elaborado pela Comissão Mundial sobre o Meio Ambiente e o Desenvolvimento da ONU em 1987, entendese que: a superação das necessidades sociais atuais não se fará mediante o dano às condições das gerações futuras de atenderem às suas próprias. Tal ideia evidencia a relação entre os seres neste planeta e entre esses e seus valores, necessidades e recursos. Na base dessa acepção está o entendimento de que a superação das mazelas sociais deve ser percebida em termos geracionais. Afinal, não há que se falar em incremento do bem-estar social se as mudanças envolvidas produzirem exclusão e outras privações futuras. Desse modo, a sustentabilidade é referenciada em termos de reprodução indefinida de cadeias funcionais reconhecidas como relevantes para atores. Ela extrapola a divisão tradicional do tempo nos planejamentos, normalmente, de curto, médio e longo prazos. E, principalmente, dissolve o olhar estabanado curtoprazista, normalmente focado, alternadamente, em retorno ou crescimento, conforme a fase do ciclo econômico. Isso torna-se relevante quando assumimos que a tendência do comportamento humano é valorizar o curto prazo, mudar tal inclinação preponderante exige racionalização contra-intuitiva e incentivos externos (Thaler, 2019). Do ponto de vista das políticas públicas, pode-se abordar a sustentabilidade por meio da investigação do impacto social esperado. Ou seja, a partir das considerações inerentes aos instrumentos econômicos tradicionais, que trabalham num horizonte de planejamento espácio-temporal muito limitado, quais outras mudanças (in)desejáveis podem decorrer da política?

O último componente da endogeneidade é a participação, enfocada pela lente da heterogeneidade de atores (Dagnino, 2002), no sentido do mais completo mapeamento dos atores interessados. Isso é relevante porque: "uma maior heterogeneidade garante maior grau de publicidade a um determinado 'público"” (Grupo de Estudos sobre a Construção Democrática, 1998, p. 63). Entende-se a publicidade no sentido mais amplo possível, desde a divulgação de todos os elementos que possam influenciar o processo decisório até o constrangimento ao segredo, possibilitando a justificação substantiva das decisões, tendo em vista a formação de interesse público genuíno. Ainda, a inserção da diversidade local nas arenas decisórias das políticas responde “[...] aos princípios e requisitos institucionais, como a descentralização, a 
transversalidade, a intersetorialidade, a participação social, a transparência etc. [...]" (Pires \& Gomide, 2016a, p. 102).

Ademais, Evans (1993) sustenta que uma rede de relações entre os diversos atores amplia a inteligência e colabora para a implementação das políticas; segundo ele: "a inserção é necessária porque as políticas devem responder aos problemas detectados nos atores privados e dependem, no final, destes atores para a sua implementação" (Evans, 1993, p. 124). Evans ressalta a interdependência de múltiplos atores nos processos de mudança social; por um lado, a participação minimiza as limitações cognitivas e informacionais, pois os atores interessados têm diferentes visões de mundo, recursos de veto e conhecimentos, o que contribui para o desenho de uma política mais ajustada aos contextos; por outro lado, a complexidade da tarefa exige diversos tipos de recursos sociais, por definição, dispersos entre os atores. Isto é, esta dimensão intenta lançar luz sobre a heterogeneidade dos interesses envolvidos no processo de mudança, quantificando e qualificando o interesse coletivo considerado pela política. Nesse sentido, a ideia de participação está relacionada mais à ideia de inserção de diversos atores com o objetivo de qualificar a tomada de decisão do que à ideia de controle externo das ações do Estado, esse seria um dos produtos possíveis de tal dinâmica.

Em síntese, as três dimensões analíticas discutidas proporcionam aproximação ao aspecto endógeno, central na perspectiva de desenvolvimento trabalhada. Isso porque elas enfocam a direção da mudança no sentido de favorecimento da condição de agência dos atores. Entendemos que nenhum objeto teria condições de esgotar as possibilidades analíticas de qualquer uma das categorias apresentadas. Algo que, caso ocorresse, limitaria a eficácia do método. Cabe agora explorar a segunda macrocategoria, os mecanismos de governança derivados.

Ainda em sentido geral, os mecanismos de governança correspondem aos arranjos institucionais voltados à articulação entre a pluralidade de atores interessados (Pires \& Gomide, 2016b). Assim, essa macrocategoria analítica busca investigar as possibilidades e os limites dos espaços de concertação no sentido de instrumentalizarem o caráter endógeno desejado. E, para fins analíticos, também foi desdobrada em três dimensões: participação, consensualidade e gestão mista.

A participação aparece novamente, dessa vez sob a ótica da normatividade, que, percebida conjuntamente à dimensão anterior, estabelece um conjunto necessário, embora não suficiente, à participação efetiva (Dagnino, 2002). Nesse sentido complementar, haveria a qualificação, sob nova dimensão, do objetivo de participação local. Isto é, que pode ser maior ou menor, e não apenas existente ou inexistente. 0 elemento refere-se à explicitação de mecanismos coercitivos/incentivos ao comportamento, (in)capazes de garantir, em variados níveis, que a heterogeneidade de atores mobilize seus recursos, se expresse e influencie os processos decisórios. Assume-se, assim, a necessidade de normas administrativas que evitem a reprodução de desigualdades preexistentes junto aos espaços decisórios e de ação (Côrtez, 2007), o que seria um impedimento à manifestação e prevalência do caráter endógeno. Com isso, investigase aqui a existência de regras escritas difundidas, informações e dados que permitam uma participação eficaz.

Por sua vez, a consensualidade objetiva perceber níveis de (dis)concordância nos contextos de ação observados. Os graus de alinhamento podem ir desde a consecução de uma lógica conflituosa, de soma zero (ganha-perde); até uma lógica cooperativa, sistêmica (ganha-ganha); desenhando um espaço infinitesimal entre um ponto e outro, entre um tipo ideal e seu oposto também ideal, conforme o caso. Trata-se, então, de observar e entender os níveis de construção de consenso para a estruturação de ação coletiva correspondente; aqueles que fornecem base para a reprodução estrutural, com ou sem mudança (Sahlins, 1990). Afinal, é difícil imaginar um contexto de ação humana em que as ações sejam coordenadas com total ausência de consenso (Fraser, 1987). Importante salientar que a dimensão não visa medir moralidade. Mesmo porque, elevados níveis de consenso tendem a reproduzir o status quo; baixos níveis de consenso, por sua vez, requerem repactuações e/ou mudança, implicando em algum tipo de destruição criativa. Desse modo, analisa-se os mecanismos de manejo de conflitos, de estabelecimento de prioridades e de produção de objetivos compartilhados entre a diversidade de agentes interessados na política. Refere-se, então, à 
qualidade da participação nos processos de decisão estratégica, desaguando no plano tático, senão, de construção hegemônica.

A gestão mista procura auferir o potencial de coordenação e de integração das ações entre as diferentes políticas e suas instituições responsáveis, evitando disputas predatórias e produzindo sinergia (efetividade). 0 objetivo último passa pelo ordenamento tático da ação coletiva, pelos métodos de implementação das políticas, mas também, pelos processos decisórios que lhe deram origem. Nesse debate, emergem as questões de coordenação e de cooperação. Os dois conceitos se referem a dinâmicas de execução de ações por meio da articulação e do compartilhamento de recursos das organizações e suas políticas (Gontijo, 2012). Outro ponto que emerge, é o da intersetorialidade: da integração das políticas de forma a responder à complexidade dos problemas sociais (Costa \& Bronzo, 2012). Aqui, a gestão passa, necessariamente, pela construção de uma estrutura institucional de forma endógena (Ostrom, 1990). A institucionalização desse tipo de regra do jogo, ou seja, de como cada ator envolvido contribuirá e se beneficiará da política, propicia o desenvolvimento e a sustentabilidade das atividades ao longo do tempo. Caso contrário, há o risco do surgimento de comportamentos predatórios ou mesmo do efeito carona, em que alguns indivíduos se beneficiam sem arcar com os custos, onerando os demais. De forma geral, essa dimensão enfoca as formas de atuação sinérgica entre políticas e organizações diferentes, que relaciona os níveis inter e intragovernamental. Observam-se, assim, instrumentos organizacionais, abarcando comparativamente tarefas e prerrogativas.

A Figura 1 mostra a dinâmica do modelo. A categoria Políticas Públicas (1) refere-se às políticas analisadas quanto a seus possíveis impactos no desenvolvimento da sociedade em foco, ou seja, constitui o contexto empírico da pesquisa. As dimensões de análise são a estrutura, os processos e os resultados destas iniciativas, as quais listamos de forma não exaustiva na terceira coluna. A partir destas dimensões ter-se-ia uma análise descritiva das políticas públicas de interesse, permitindo compreender seu arranjo e dinâmica. Já as categorias analíticas do modelo são a Endogeneidade (2) e os Mecanismos de Governança (3). A categoria Endogeneidade tem suas formas de mensuração nas dimensões equidade, sustentabilidade e participação, cujas definições constam na terceira coluna. A categoria Mecanismos de Governança é medida por meio das dimensões participação, consensualidade e gestão mista, definidas na terceira coluna. Cabe ressaltar que tais definições sintéticas respondem à derivação conceitual apresentada anteriormente. Por sua vez, a categoria Perspectiva do Desenvolvimento (4) aparece como o resultado auferido pelo modelo, no sentido de que, quanto melhor forem atendidas as categorias relativas à Endogeneidade e aos Mecanismos de Governança, maior seria o impacto, em termos de desenvolvimento multidimensional das políticas analisadas. Ou ainda, quanto mais aderentes forem os Mecanismos de Governança à Endogeneidade expressada, maior o potencial de efetividade das políticas analisadas, em termos de desenvolvimento multidimensional.

Assim, a categoria Perspectiva do Desenvolvimento constituiu a variável dependente do modelo, uma vez que está em investigação a capacidade das políticas públicas de produzirem mudanças sociais complexas, traduzidas aqui enquanto desenvolvimento multidimensional. Para tanto, extraímos desta concepção as categorias de análise e suas dimensões, permitindo avaliar o potencial de desenvolvimento das políticas, bem como identificar lacunas e possibilidades de incremento. Assim, este modelo sustenta que as políticas que melhor encaminharem as categorias endogeneidade e mecanismos de governança, conforme acepções desenhadas previamente, terão maiores condições de alcançarem efeitos em termos de desenvolvimento multidimensional. 


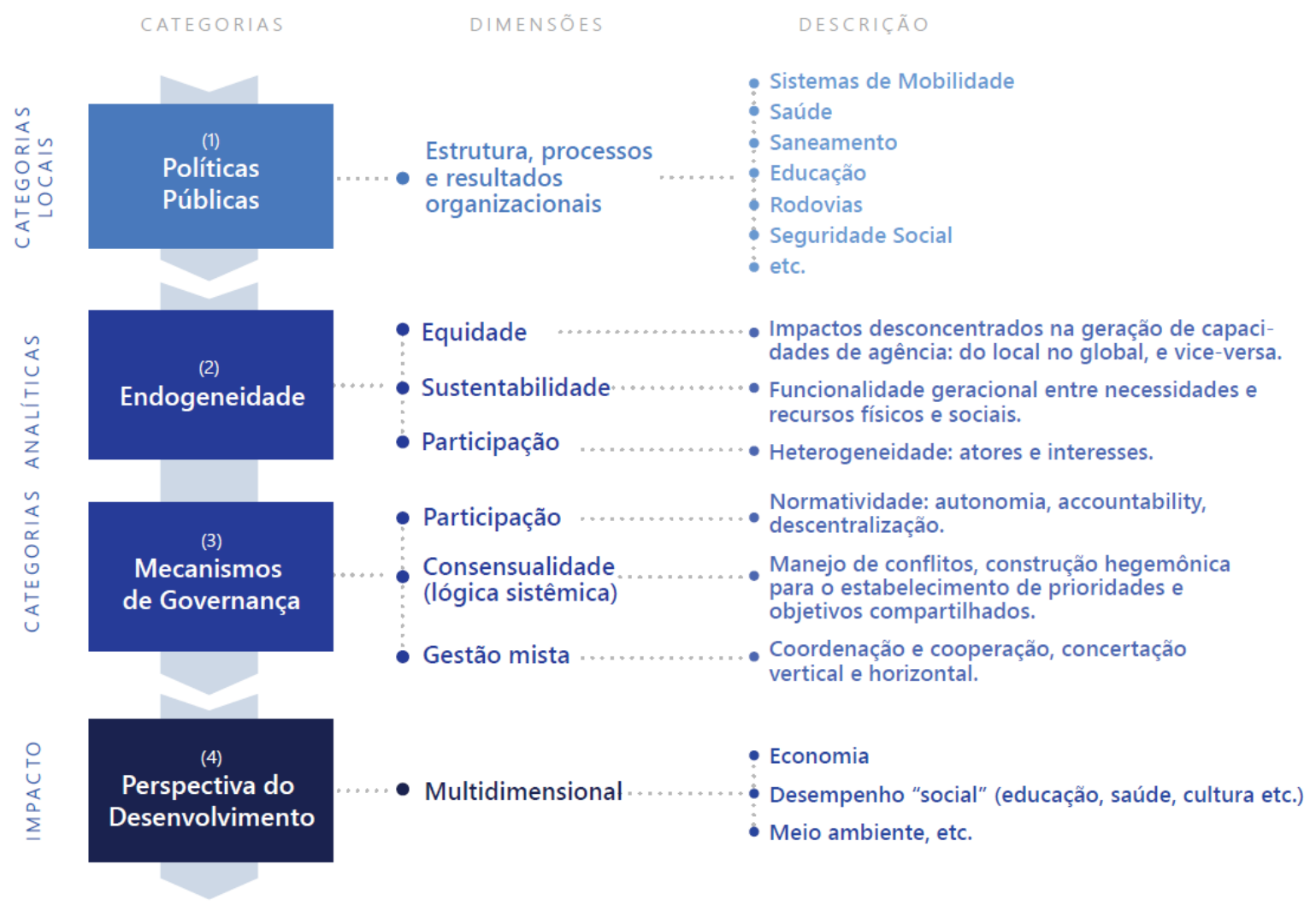

Figura 1 - Modelo de análise para políticas públicas a partir de uma perspectiva de desenvolvimento multidimensional. Fonte: elaboração própria.

Enfim, o modelo de análise proposto sugere que examinemos as políticas públicas para além da eficácia alcançada setorialmente, o que já haveria justificado sua existência; indo em direção à capacidade para promover uma mudança social mais desconcentrada, ganhando direção e sentido prospectivo, de desenvolvimento multidimensional. Assim, apresentamos dois conjuntos de categorias analíticas: endogeneidade e mecanismos de governança; por sua vez, subdivididas em dimensões que permitissem segmentá-las conceitualmente, explorando as diversas nuances dos processos gerados no escopo de cada política analisada. Estas dimensões funcionam como métricas, para além da eficácia particular individualmente alcançada por cada política, medindo a contribuição à efetividade conseguida apenas conjuntamente.

\section{Considerações finais}

O campo das políticas públicas vem exibindo um grande dinamismo no Brasil nas últimas décadas (Vendramini \& Almeida, 2017; Marques \& Faria, 2013). Com isso, vemos uma aproximação e difusão das diversas abordagens de análise existentes. Neste âmbito, almejamos contribuir com a literatura por meio do delineamento de um modelo analítico que permita compreender as políticas à luz de categorias de efetividade transversais às eficácias individuais, aos efeitos sociais específicos ambicionados. Em tal construção, acionamos um pressuposto: de que desejamos que as políticas públicas restem integradas quanto à produção de bem-estar social, sinergicamente, tratado aqui como desenvolvimento multidimensional.

Nesse caminho, partimos de uma definição de políticas públicas que salienta sua abrangência e finalidade múltipla: mudar uma dada realidade social. Uma pretensão de transformação social gerenciada que precisa ser devidamente qualificada, medida e integrada às outras políticas atuantes, que ajudam a formar o contexto de implementação. Um entendimento que demanda ser desmembrado, em meio a uma 
perspectiva analítica sensível a elementos ligados à mudança social. Localizamos na literatura sobre desenvolvimento endógeno um meio profícuo para realizar tal tarefa. Para isso, fomos para além da mudança pretendida pela política (eficácia), por meio de instrumentos causadores de efeitos desconcentrados (efetividade), em termos de desenvolvimento multidimensional. Nesse caminho, derivamos dois conjuntos de categorias analíticas: endogeneidade e mecanismos de governança.

A endogeneidade atenta para o manancial dos potenciais de agência dos atores locais e para suas decorrências, funcionais e/ou complexas. Isso é relevante uma vez que eles, conscientemente ou não, são os empreendedores que produzem os processos e sofrem as consequências das ações correspondentes. Essa categoria pôde ser desdobrada em três dimensões: equidade, sustentabilidade e participação. A equidade abarca e contextualiza a relação entre igualdade e justiça, correspondendo ao incremento das capacidades de agência, com maior potencial junto aos atores mais vulneráveis. No que tange às políticas públicas, tratarse-ia do estabelecimento de foco, em uma visão de justiça social. A sustentabilidade é referenciada em termos da reprodução indefinida de cadeias funcionais relevantes; ela atenta para a superação da temporalidade tradicional, para além do longo prazo. Dirige, assim, o olhar para as futuras gerações e, nas políticas, uma aproximação possível é por meio do impacto social esperado. Já a participação lança luz sobre a heterogeneidade dos interesses envolvidos no processo de mudança. A intenção aqui é investigar a aderência das políticas para realizar aquilo que justifica sua existência: melhorar a vida em sociedade, investigando suas possibilidades de integração sinérgica ao contexto, quanto à produção de desenvolvimento multidimensional.

Por sua vez, os mecanismos de governança enfocam os processos de construção política das políticas, com vistas a verdadeiramente possibilitar a manifestação do caráter endógeno na estrutura e nos processos de tomada de decisão, provendo voz, estratégia e tática à consecução da visão local de desenvolvimento. Também decomposto em três dimensões: participação, consensualidade e gestão mista. A participação aparece novamente, demonstrando sua centralidade. Aqui, sua importância concerne à normatividade: à explicitação de mecanismos balanceadores de recursos de poder prévios, capazes de garantir que aquela heterogeneidade se expresse e influencie os processos decisórios. A consensualidade tange à consecução de uma lógica sistêmica, em contraposição à lógica de soma zero. Desse modo, analisa-se os mecanismos de manejo de conflitos, de estabelecimento de prioridades e de produção de objetivos. Já a gestão mista diz respeito ao ordenamento tático da ação coletiva, observada em termos de instrumentos de coordenação e de integração, abarcando a divisão de tarefas e prerrogativas. O propósito é investigar as possibilidades e os limites dos espaços de concertação em relação ao caráter endógeno.

Enfim, o modelo propõe investigar as políticas a partir de categorias exógenas a elas, mas alinhadas às fontes de sua legitimidade. Com isso, nos afastamos do viés top-down ao mesmo tempo em que nos aproximamos de uma metodologia horizontal, de tomada de decisão descentralizada e efeitos desconcentrados.

Cabe indicar alguns possíveis limites do modelo. Deve-se atentar que a base teórica foi desenvolvida a partir de um olhar para a América Latina e países europeus de desenvolvimento tardio, o que pode não se ajustar à análise de experiências de países de capitalismo avançado. Em segundo lugar, a amplitude das categorias se pretende inclusiva em termos de setores de políticas públicas, contudo, é relevante observar se isso se confirma na aplicação. Em terceiro lugar, as categorias analíticas podem ser mais abrangentes do que os objetivos de pesquisa, o que gerará a necessidade de adaptação. Todas essas questões, e outras que surgirão do manuseio da abordagem, podem ser vistas como espaços de criatividade, nos quais pesquisadoras e pesquisadores poderão movimentar-se sempre guiados pelo problema de pesquisa. Também, a proposta não exige uma metodologia específica, a qual, igualmente, é orientada pela problemática e objeto da investigação. No mais, entendemos que todo conhecimento é transitório, devendo ser continuamente trabalhado, criticado e desenvolvido. 


\section{Referências}

Abers, R. N., Silva, M. K., \& Tatagiba, L. (2018). Movimentos sociais e políticas públicas: repensando atores e oportunidades políticas. Lua Nova, 105, 15-46.

Acemoglu, D., \& Robinson, J. (2015). Por que as nações fracassam: as origens do poder, da prosperidade e da pobreza. São Paulo: Elsevier Brasil.

Adachi, V. (2019, August 30). Lucro com causa, o novo normal dos negócios. Valor Econômico.

Albuquerque, F. (2004). Desarrollo económico local y descentralización en América Latina. Revista de La CEPAL, (82), 157171.

Araújo, L., \& Rodrigues, M. L. (2017). Modelos de Análise das Políticas Públicas. Sociologia, Problemas e Práticas, 83, 11-35.

Arretche, M. (2016). Prefácio. In T. Menicucci \& J. G. L. Gontijo (Eds.), Gestão e políticas públicas no cenário contemporâneo (pp. 11-13). Rio de Janeiro: Fiocruz.

Avritzer, L., \& Souza, C. H. L. (Eds.). (2013). Conferências nacionais: atores, dinâmicas participativas e efetividade. Brasília: Ipea.

Bardach, E. (2012). A practical guide for policy analysis: the eightfold path to more effective problem solving (4th ed.). Los Angeles: SAGE.

Barros, A. A., \& Castro, C. H. S. (2013). Gestão social e gestão pública no desenvolvimento local. Cadernos de Desenvolvimento, 8(12), 147-162.

Baugartner, F., \& Jones, B. (1993) Agendas and Instability in American Politics. Chicago: University of Chicago Press.

Bevir, M. (2013). Governance as theory, practice, and dilemma. In M. Bevir (Ed.), The Sage Handbook of Governance (pp. 116). Los Angeles: SAGE.

Borba, J., \& Lüchmann, L. H. H. (2010). A representação política nos Conselhos Gestores de Políticas Públicas. Revista Brasileira de Gestão Urbana, 2(2), 229-246.

Boullosa, R. de F., \& Rodrigues, R. W. S. (2014). Avaliação e monitoramento em gestão social: notas introdutórias. Revista Interdisciplinar de Gestão Social, 3(3), 145-178.

Brugué, Q., Gomà, R., \& Subirats, J. (2005). Gobernar ciudades y territorios en la sociedad de las redes. Revista Del CLAD Reforma y Democracia, (32), 1-8.

Capano, G., \& Howlett, M. (2020). The Knowns and Unknowns of Policy Instrument Analysis: Policy Tools and the Current Research Agenda on Policy Mixes. SAGE Open, 10(1), 1-13.

Castro, J. A., \& Oliveira, M. G. (2014). Políticas públicas e desenvolvimento. In L. M. Madeira (Ed.), Avaliação de políticas públicas 2 (pp. 20-48). Porto Alegre: UFRGS/CEGOV.

Casula, M. (2017). Quem governa na governança (local)? Reflexões teóricas e evidências empíricas. Revista de Administração Pública-RAP, 51(6), 1122-1138.

Cohen, E., \& Franco, R. (2007). Gestão social: como obter eficiência e impacto nas políticas sociais. Brasília: Enap.

Cohen, M., March, J., \& Olsen, J. (1972). A Garbage Can Model of Organizational Choice. Administrative Science Quarterly, 17, $1-25$.

Côrtez, S. V. (2007). Viabilizando a participação em conselhos de políticas públicas municipais: arcabouço institucional, organização do movimento popular e policy communities. In Hochman, G., Arretche, M., \& E. Marques (Eds.), Políticas Públicas no Brasil (1 ed., pp. 125-144). Rio de Janeiro: Fiocruz.

Costa, B. L. D., \& Bronzo, C. (2012). Intersetorialidade no enfrentamento da pobreza: o papel da implementação e da gestão. In C. A. P. Faria (Ed.). Implementação de Políticas Públicas: teoria e prática 2 (pp. 50-81). Belo Horizonte: PUC Minas.

Dagnino, E. (Ed.). (2002). Sociedade civil e espaços públicos no Brasil. São Paulo: Brasiliense.

Dallabrida, V. R. (2011). Economia, Cultura e Desenvolvimento: uma primeira aproximação sobre as origens teóricas da abordagem do tema. Revista Brasileira de Gestão e Desenvolvimento Regional, 7(2), 282-299.

Delgado, N. G., \& Leite, S. P. (2011). Políticas de desenvolvimento territorial no meio rural brasileiro: novas institucionalidades e protagonismo dos atores. DADOS-Revista de Ciências Sociais, 54(2), 431-473. 
Dietz, T., Ostrom, E., \& Stern, P. C. (2003). The struggle to govern the commons. Science, 302(5652), 1907-1912.

Docampo, M. G. (2007a). El desarrollo local en el marco de los procesos de globalización. In Docampo, M. G. (Ed.), Perspectivas teóricas en Desarrollo Local (pp. 1-37). La Coruna: Netbiblo.

Docampo, M. G. (Ed.). (2007b). Perspectivas teóricas en desarrollo local. La Coruna: Netbiblo.

Draibe, S. M. (2001). Avaliação de implementação: esboço de uma metodologia de trabalho em políticas públicas. In M. C. R. N. Barreira \& M. do C. B. Carvalho (Eds.). Tendências e perspectivas na avaliação de políticas e programas sociais (pp. 13-42). São Paulo: IEE/PUC-SP.

Dye, T. R. (2010). Understanding public policy (13 ${ }^{\text {th }}$ ed.). Boston: Longman.

Evans, P. (2004). Autonomia e parceria: Estados e transformação industrial. Rio de Janeiro: UFRJ.

Evans, Peter. (1993). 0 Estado como problema e solução. Lua Nova: Revista de Cultura e Política, (28-29), $107-157$.

Farah, M. F. S. (2004). Gênero e políticas públicas. Estudos Feministas, 12(1), 47-71.

Farah, M. F. S. (2018). Abordagens teóricas no campo de política pública no Brasil e no exterior: do fato à complexidade. Revista Do Serviço Público, 69, 53-84.

Favareto, A., \& Lotta, G. (2017). Inovações institucionais nas políticas para o desenvolvimento territorial em três estados brasileiros. Redes (Santa Cruz Do Sul. Online), 22(3), 11-38.

Ferrarezi, E., \& Rua, M. G. (2018). A implementação do Programa Bolsa Família: formulação em processo. In Ximenes, D. A. (Ed.). Implementação de Políticas Públicas: questões sistêmicas, federativas e intersetoriais 2 (pp. 63-96). Brasília: Enap.

Fraser, N. (1987). $O$ que é crítico na teoria crítica? O argumento de Habermas e o gênero. In Benhabibi, S., \& Cornell, D. (Eds.). Feminismo como crítica da modernidade (pp. 38-65). Rio de Janeiro: Rosa dos Tempos.

Frey, K, Oliveira, V. E., Ximenes, S. B., Bittencourt, L. N., \& Lotta, G. S. (2017). Políticas públicas em perspectiva comparada: proposta de um framework para a análise de experiências locais. Revista Do Serviço Público, 68(1), 9-36.

Giddens, A. (1998). Política, sociologia e teoria social: encontros com o pensamento social clássico e contemporâneo. São Paulo: Unesp.

Gomide, A. de Á., \& Pereira, A. K. (2018). Capacidades estatais para políticas de infraestrutura no Brasil contemporâneo. Revista de Administração Pública, 52(5), 935-955.

Gontijo, J. G. L. (2012). Coordenação, cooperação e políticas públicas: organizando percepções e conceitos sobre um tema caro à implementação. In Faria, C. A. (Ed.). Implementação de Políticas Públicas: teoria e prática (pp. 82-122). Belo Horizonte: PUC Minas.

Grupo de Estudos sobre a Construção Democrática. (1998). Esfera pública e democracia no Brasil. Ideias, 5(2), 43-74.

Heidemann, F. G. (2014). Do sonho do progresso às políticas de desenvolvimento. In Heidemann, F. G., \& J. F. Salm (Eds.), Políticas Públicas e Desenvolvimento: bases epistemológicas e modelos de análise (3 ${ }^{\text {rd }}$ ed., pp. 21-49). Brasília: UNB.

Hill, M., \& Hupe, P. (2014). Implementing public policy (3rd ed.). London: SAGE.

Howlett, M., Ramesh, M., \& Perl, A. (2013). Política Pública: seus ciclos e subsistemas: uma abordagem integradora. Rio de Janeiro: Elsevier.

Inglehart, R., \& Welzel, C. (2009). Modernização, mudança cultural e democracia (1st ed.). São Paulo: Francis.

Kerstenetzky, C. L. (2006). Políticas Sociais: focalização ou universalização. Revista de Economia Política, 26(4), 564-574.

Kingdon, J. W. (1995). Agendas, alternatives, and public policies (2nd ed.). New York: HarperCollins College Publishers.

Kliksberg, B. (1997). O desafio da exclusão: para uma gestão social eficiente. São Paulo: FUNDAP.

Lasswell, H. D. (1956). The Decision Process. Seven Categories of Functional Analysis, College Park, MD. Maryland: University of Maryland Press.

Lavalle, A. G., Voigt, J., \& Serafim, L. (2016). 0 que fazem os conselhos e quando o fazem? Padrões decisórios e o debate dos efeitos das instituições participativas. Dados-Revista de Ciências Sociais, 59(3), 609-650.

Leal, A. F., \& Lui, L. (2018). Instituições participativas e seus efeitos nas políticas públicas: estudo do Comitê de Mortalidade por Aids de Porto Alegre. Saúde e Sociedade, 27, 94-105. 
Lima, L. L.; D’Ascenzi, L. (2019). Implementação e avaliação de políticas públicas: intersecções, limites e continuidades. In: Lotta, G. (Ed.). Teorias e Análises sobre Implementação de Políticas Públicas no Brasil 9pp. 127-152). Brasília: Enap.

Lindblom, C. E. (1979) “Still Muddling, Not Yet Through”, Public Administation Review, 39, 517-526.

Lotta, G., \& Favareto, A. (2016). Desafios da integração nos novos arranjos institucionais de políticas públicas no Brasil. Revista de Sociologia e Política, 24(57), 49-65.

Lotta, G. S. (Ed.). (2019). Teorias e Análises sobre Implementação de Políticas Públicas no Brasil. Brasília: Enap.

Lowi, T. (1964) American Business, Public Policy, Case Studies and Political Theory, World Politics, 16, 677-715.

Lucio, M. L., Daroit, D., \& Freitas, U. F. C. (2017). Desenvolvimento, ação pública e transversalidade dos instrumentos de gestão: um olhar sobre o programa Bolsa Família. In Lima, L. L., \& Rodrigues, M. I. (Eds.). Campo de pública em ação: cooletânea em teoria e gestão de políticas públicas (pp. 292-313). Porto Alegre: UFRGS/CEGOV.

Marques, E., \& Faria, C. A. P. (Eds.). (2013). A política pública como campo multidisciplinar. São Paulo: Editora UNESP.

Mauro, R. de A., Cintrão, J. F. F., Melhen, J. E., \& Oliveira, E. A. (2018). Dimensões do Desenvolvimento Territorial e Políticas Públicas: Perspectivas e Desafios a Partir da Constituição Federal de 1988. Revista de Gestão Ambiental e Sustentabilidade, 7(3), 489-506.

Muller, P., \& Surel, Y. (2002). A análise das políticas públicas. Pelotas: EDUCAT.

Neto, A. M. (Ed.). (2014). Sociedade, política e desenvolvimento. Brasília: Ipea.

Nogueira, C. A. G., \& Forte, S. H. A. C. (2019). Efeitos intersetoriais e transversais e seus impactos sobre a efetividade das políticas públicas nos municípios do Ceará. Revista de Administração Pública.

Ostrom, E. (1990). Governing the commons: The evolution of institutions for collective action. Cambridge: Cambridge University Press.

Peters, B. (2015). Advanced introduction to public policy. Massachusetts: Edward Elgar.

Pimenta, C. A. M. (2014). Tendências do desenvolvimento: elementos para reflexão sobre as dimensões sociais na contemporaneidade. Revista Brasileira de Gestão e Desenvolvimento Regional, 10(3), 44-66.

Pires, R. R. C. (Ed.). (2019a). Implementando desigualdades: reprodução de desigualdades na implementação de políticas públicas. Rio de Janeiro: Ipea.

Pires, R. R. C. (2019b). Introdução. In R. R. C. Pires (Ed.), Implementando Desigualdades: Reprodução de Desigualdades na Implementação de Políticas Públicas (pp. 13-50). Rio de Janeiro: Ipea.

Pires, R. R. C., \& Gomide, A. de Á. (2016a). Governança, arranjos institucionais e capacidades estatais na implementação de políticas federais. In Menicucci, T. \& Gontijo, J. G. L. (Eds.). Gestão e políticas públicas no cenário contemporâneo (pp. 101127). Rio de Janeiro: Fiocruz.

Pires, R. R. C., \& Gomide, A. de Á. (2016b). Governança e capacidades estatais: uma análise comparativa de programas federais. Revista de Sociologia e Política, 24(58), 121-143.

Polski, M. M., \& Östrom E. (1999) An Institutional Framework for Policy Analysis and Design. Workshop in Political Theory and Policy Analysis Indiana University. Bloomington, Workshop Working Paper Series, W, 98-27.

Radomsky, W., \& Francisco, G. (2011). Desenvolvimento, pós-estruturalismo e pós-desenvolvimento: a crítica da modernidade e a emergência de" modernidades. Revista Brasileira de Ciências Sociais, 26(75), 149-162.

Rebelatto, D. (2004). Avaliação social de projetos. In Rebelatto, D. (Ed.). Projeto de Investimento (pp. 239-269). São Paulo: Manole.

Reis, E. (2003). Reflexões leigas para a formulação de uma agenda de pesquisa em políticas públicas. Revista Brasileira de Ciências Sociais, 18(51), 11-14.

Rodrigues, L. C. (2008). Propostas para uma avaliação em profundidade de políticas públicas sociais. Revista Avaliação de Políticas Públicas-AVAL, 1(1), 7-15.

Rodrigues, M. I., \& Beserra, J. (2017). Compras públicas sustentáveis: uma análise a partir do tripé da sustentabilidade. In Lima, L., \& Rodrigues, M. I. (Eds.). Campo de pública em ação: coletânea em teoria e gestão de políticas públicas (pp. 84-115). Porto Alegre: UFRGS/CEGOV. 


\section{Políticas públicas e desenvolvimento}

Sabatier, P., \& Jenkins-Smith, H. (1993). Policy Change and Learning: The Advocacy Coalition Approach. Boulder: Westview Press.

Sahlins, M. (1990). Ilhas de história. Rio de Janeiro: Zahar.

Santos, E., Braga, V., Santos, R., \& Braga, A. (2012). Desenvolvimento: um conceito em construção. DRd - Desenvolvimento Regional Em Debate, 2(1), 44-61.

Santos, M. J., \& Carniello, M. F. (2014). História do desenvolvimento: limites de um campo de pesquisa. Revista Brasileira de Gestão e Desenvolvimento Regional, 10(3), 67-88.

Secchi, L. (2015). Políticas Públicas: conceitos, esquemas de análise, casos práticos (2 ${ }^{\text {nd }}$ ed.). São Paulo: Cengage Learning.

Sen, A. (2010a). Desenvolvimento como liberdade. São Paulo: Companhia das Letras.

Sen, A. (2010b). Exclusão e inclusão. In Sen, A., \& Kliksberg, B. (Eds.). As pessoas em primeiro lugar: a ética do desenvolvimento e os problemas do mundo globalizado (pp. 33-63). São Paulo: Netbiblo.

Sen, A., \& Kliksberg, B. (2010). As pessoas em primeiro lugar: a ética do desenvolvimento e os problemas do mundo globalizado. São Paulo: Companhia das Letras.

Souza, C. M. (2006). Políticas públicas: uma revisão da literatura. Sociologias, 8(16), 20-45.

Souza, C. M. (2007). Estado da arte da pesquisa em políticas públicas. In Hochman, G., Arretche, M., \& Marques, E. (Eds.). Políticas Públicas no Brasil (pp. 65-86). Rio de Janeiro: Fiocruz.

Tapia, J. R. B. (2005). Desenvolvimento local, concertação social e governança: a experiência dos pactos territoriais na Itália. São Paulo. Em Perspectiva, 19(1), 132-139.

Thaler, R. H. (2019). Misbehaving (1 ${ }^{\text {st }}$ ed.). Rio de Janeiro: Intrínseca.

Vázquez Barquero, A. (2007). Sobre la diversidad de las interpretaciones y la complejidad del concepto de desarrollo endógeno (pp. 39-58). In Docampo, M. G. (Ed). Perspectivas Teóricas en Desarrollo Local. La Coruña, Espanha: Netbiblo,

Vázquez Barquero, A. (2001). Desenvolvimento endógeno em tempos de globalização. Porto Alegre: Fundação de Economia e Estatística.

Vendramini, P., \& Almeida, L. S. B. (Eds.). (2017). Pioneirismo, renovação e desafios: experiências do Campo de Públicas no Brasil. Florianópolis: UDESC.

Vieira, E. T., \& Santos, M. J. (2012). Desenvolvimento econômico regional-uma revisão histórica e teórica. Revista Brasileira de Gestão e Desenvolvimento Regional, 8(2), 344-369.

Editor responsável: Rodrigo Firmino

Recebido: 22 fev. 2021

Aprovado: 05 jul. 2021 